\title{
The amplitude influence on the thermal and hydraulic performances for a wavy air fin in a compact heat exchanger used in agriculture applications
}

\author{
Septimiu Albețel ${ }^{1,2, *}$, Alexandru Rus ${ }^{1,2}$, Eveline David ${ }^{1}$, and Vlad Marțian ${ }^{2}$ \\ ${ }^{1}$ Politehnica Timișoara, Mechanical Faculty, 1 M. Viteazu Streeet, Timişoara, Romania \\ ${ }^{2}$ RAAL S.A., Technical Department, 7 Industriei street, Bisțrita, Romania
}

\begin{abstract}
Wavy air fins are used in the construction of aluminum compact heat exchangers which are used in thermal equipment for agriculture, construction, and industrial applications. Since atmospheric air convective heat transfer coefficient is among the lowest of all fluids, there is a special interest in the optimizing of the geometry for this type of heat exchangers. One of the biggest challenges in designing cooling solutions for agriculture applications is the clogging effect on the performances of the heat exchangers. Clogging leads to a critical performance reduction of the compact heat exchanger used for these types of applications. This specific study, which was conducted in RAAL S.A company in collaboration with the University "Politehnica" of Timisoara", checks the influence of the wavy air fin amplitude on the thermal and hydraulic performances and tries to find an optimum solution suitable for these specific projects. So, starting from the standard existing amplitude, different amplitude values were studied analytically. The analytical studies were further confirmed by real life measurements. The scope of the study was to find an optimal value for the amplitude that can further improve the overall performance of the aluminum compact heat exchangers and reduce the clogging effect.
\end{abstract}

\section{Introduction}

Wavy air fins such as the one from Fig. 1, are the most commonly means of extending the heat transfer surfaces in aluminum compact heat exchangers cooled by air. The wavy fin has also the role of intensifying the heat rejection by breaking the thermal boundary

\footnotetext{
${ }^{*}$ Corresponding author septimiu.albetel@,raal.ro
} 
layer inducing turbulence and a better mixing of the air through the heat exchanger. Due to its resistance to damage and its lower degree of clogging than other types of extended surfaces, such as louvered fins, this type of fin is used almost exclusively in the construction of compact heat exchangers which are used in thermal equipment for agriculture, construction, and industrial applications.

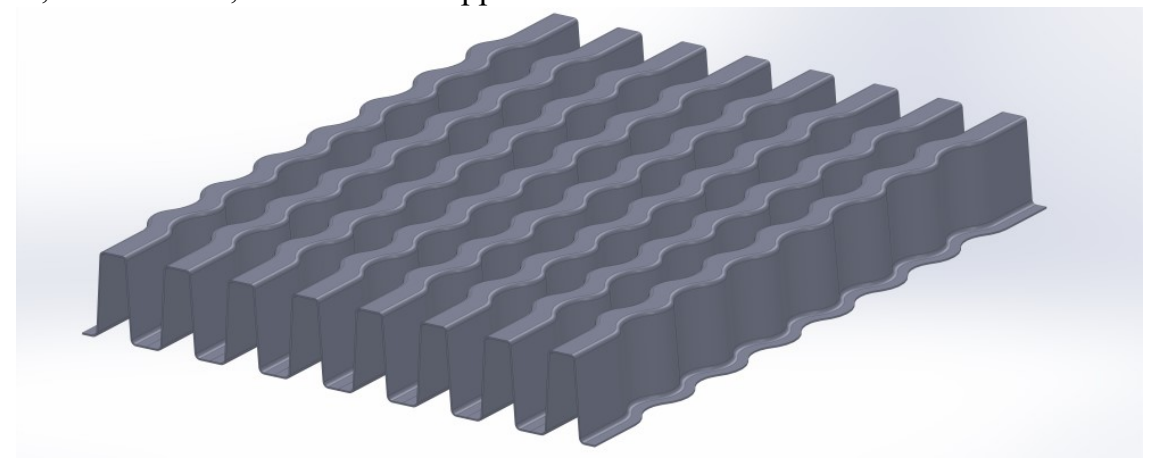

Fig. 1. Wavy fin isometric view

The above stated facts taken in conjunction with the fact that the atmospheric air convective heat transfer coefficient is among the lowest of all fluids, the wavy fin was studied since 1950 when Kays and London [1] have presented thermal and hydraulic performance charts for 3 variations of this wavy fin, without presenting analytical equations. Later, Beng and MPhil [2] have presented experimental and analytical data for 3 types similar with those of Kays and London. There have been papers presenting numerical investigation of the lateral vortexes in the low Reynolds Number domain $[10 \leq \mathrm{Re} \leq 1000]$ such as Zhang et. al. [3], and Metwally et. al. [4]. A variation of the wavy fin was numerically studied by Wang and Chen [5] as a convergent divergent way channel for $\operatorname{Re} \leq 700$ and reached the conclusion that the greatest influence in heat transfer increase is due to the first wave the rest of the waves having only a marginal influence. Gadeck [6] studied corugated channels on a much larger Reynolds numbers $(0 \leq \mathrm{Re} \leq 7500)$ containing all the flow regimes from laminar to turbulent, he then comparred the results with the flow between two plates and reach the conclusion that the corrugated chanels transfers the heat 2 times better. In his paper Ismail [7] numerically studied the wavy and offset fins and proposed criterial relations for $f$, and $j$. Dong in his papers [8]-[10] studied the effect of pitch, height and thickness of the wavy fin experimentally and numerically. In recent years there are several papers that have sumarizes and generalizes the criterial relations obtained on the wavy fin from these the one of the Aliabadi et. al. [11] which compares different relations using different fluids, Gum [12] studied a variation of wavy fin by creating cross cuts. Xiao [13] studied the performances of the wavy fin in evaporative cooling conditions, and the one of the Qasem et. al. [14] which generalizes the criterial relations of the performances for the wavy fin found in the literature.

The wavy fin presented in Fig. 1 is different from the rest of the wavy fins from the presented literature by having a straight section at the inlet and outlet of the passage. This straight section was introduced to reduce the pressure drop of this kind of fin. Studies on this specific type of fin can be found in [15], [16] which study the height and the straight section influence on the wavy fin performances.

Even if this kind of fin has a lower clogging factor this is still one of the biggest challenges in designing cooling solutions for agriculture applications. Clogging leads to a critical performance reduction of the compact heat exchanger used for these types of applications. 
This paper presents a numerical study of the influence of the wavy air fin amplitude on the thermal and hydraulic performances of a coolant to air compact heat exchanger. The numerical data is validated using experimental data from a production cooler.

\section{Experimental Setup}

The thermal and hydraulic test bench used for this study can be seen in Fig. 2. It can make acquisitions for different types of fluids (air, water, and oil) in different working conditions.

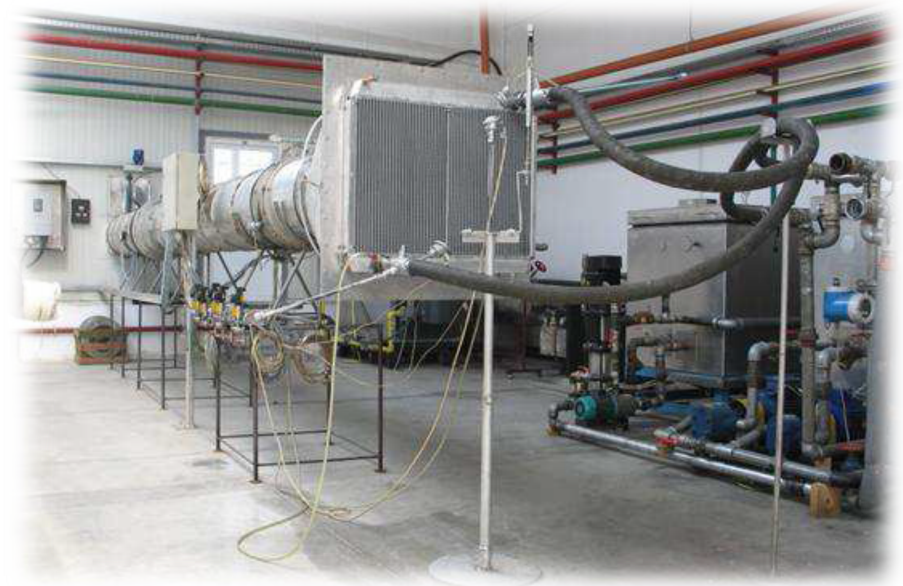

Fig. 2. Thermal and hydraulic performance test bench at RAAL S. A.

The main components of this test bench, see Fig. 3, are the wind tunnel, the fluid loop, and the tested sample.

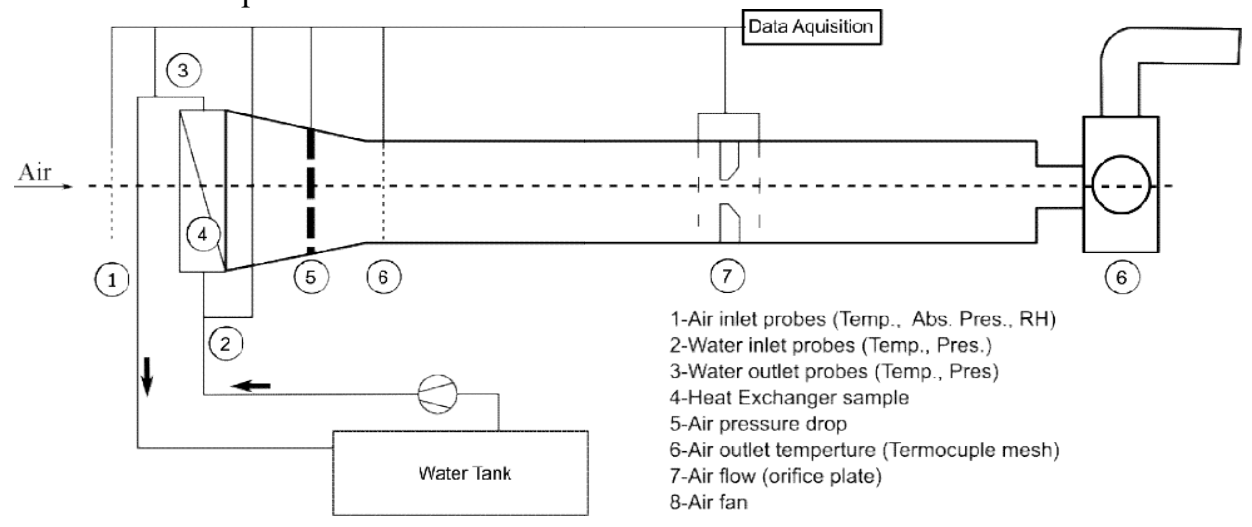

Fig. 3. Test bench functional sketch

The cooling air data is obtained using K-thermocouples, barometric pressure and relative humidity sensors each having an accuracy of $0.2 \%$ of the entire measurement domain and thermocouples for relative humidity [15]. The exit temperature is measured using a mesh of $10 \mathrm{~K}$-thermocouples to evaluate the non-uniformity of the air temperature. All the used thermocouples are pre-calibrated with an accuracy of $0.1\left[{ }^{\circ} \mathrm{C}\right]$. The air flow is measured by means of pressure differential device, i.e. orifice plate, in conformity with EN ISO 5167-2 [17]. 


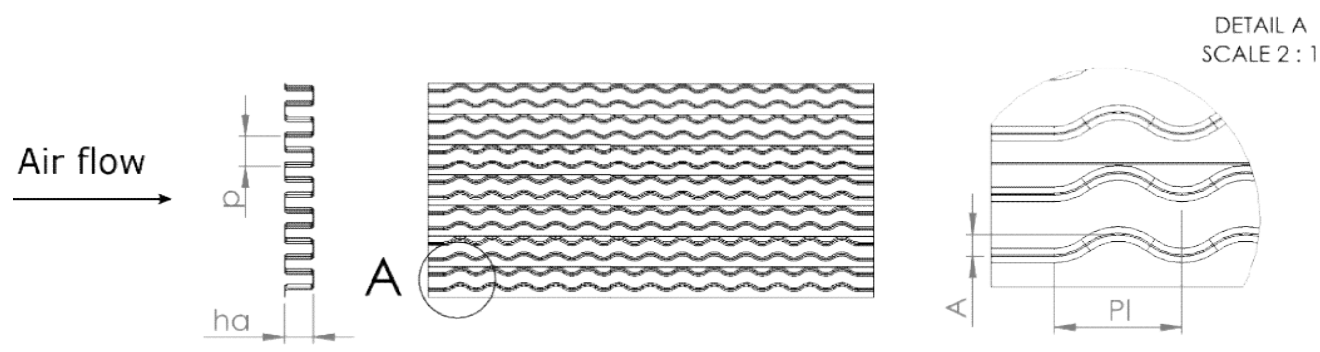

Fig. 4. Wavy fin dimensions.

For the validation of the numerical study, a test was performed on a sample water cooler that was built using a $9 \mathrm{~mm}$ fin height, $8 \mathrm{~mm}$ fin pitch and a $1.7 \mathrm{~mm}$ fin amplitude, as in Fig. 4. The measurements were made using as hot fluid $100 \%$ pure water at an inlet temperature of $88{ }^{\circ} \mathrm{C}$ with a maximum deviation of $\pm 2\left[{ }^{\circ} \mathrm{C}\right]$. For the cooling air flow the measured inlet temperature was $20\left[{ }^{\circ} \mathrm{C}\right]$ with a maximum deviation of $\pm 2\left[{ }^{\circ} \mathrm{C}\right]$. The cooling air frontal area speed ranged from $7[\mathrm{~m} / \mathrm{s}]$ up to $13[\mathrm{~m} / \mathrm{s}]$.

In order to make the experimental data independent of the test conditions we used the well-known $\epsilon$-NTU methodology [18] to express the performances of the heat exchanger in Nusselt number versus Reynolds Number, see Fig. 5, also the hydraulic performances are express a friction coefficient as defined by Kays and London [1]
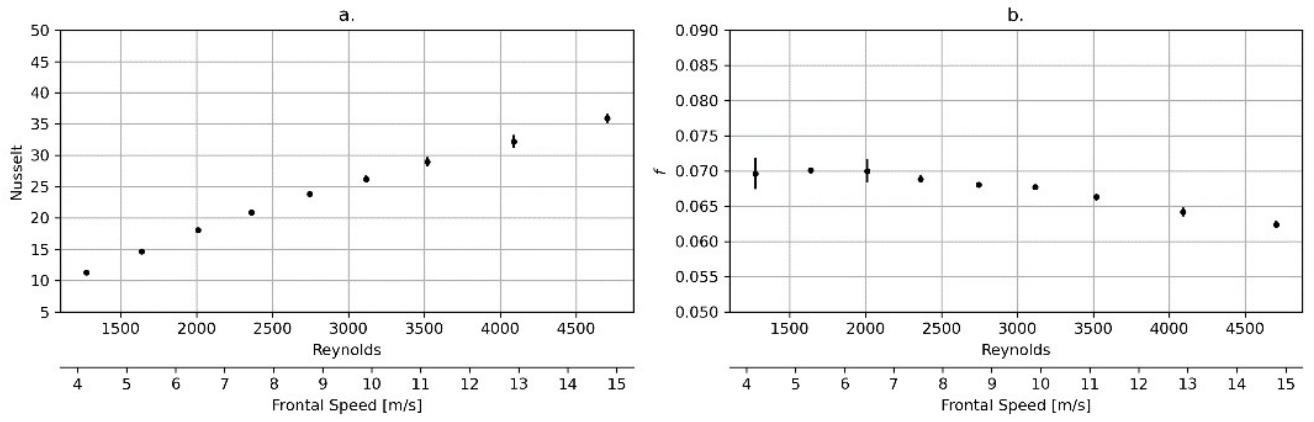

Fig. 5. Experimental dimensionless data. a. Nusselt vs Reynolds, b. friction vs Reynolds

\section{Numerical simulation}

The numerical simulations were done using the SolidWorks Flow Simulation package [19] which has a Cartesian grid system and a proprietary k- $\epsilon$ turbulence model implemented. Firstly, the wavy fin was simplified to reduce the computational time. For the simulation was used only a single fin as in the Fig 5 where we used the periodic boundary condition on the $\mathrm{z}$ axis. The water temperature was simulated by imposing a constant temperature on the top and bottom walls. The simulation domain was extended at the inlet and outlet of the fin to accommodate with the simulation software's constrains. At the inlet boundary a constant speed and temperature is applied, and at the exit boundary a constant pressure is applied. 


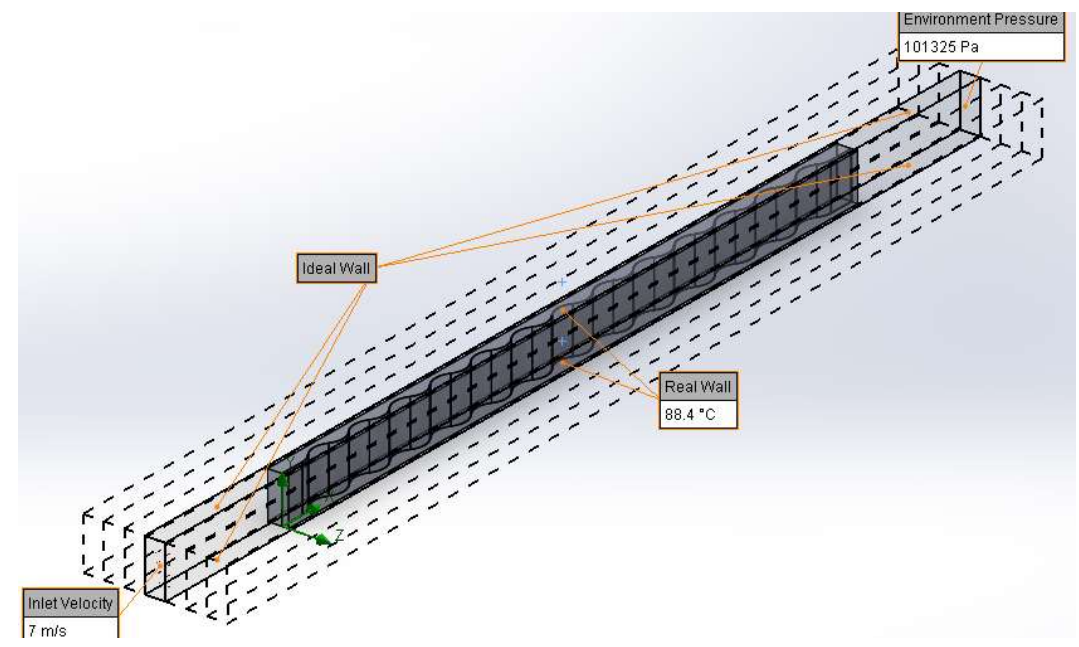

Fig. 6 Simulation domain and boundary conditions

Validation of the numerical model was done in two steps:

Firstly, we had to achieve a mesh for which the results are independent of the discretization. For this we ran the simulations with 4 different meshes discretization.

To assess the mesh convergence, we used 3 physical quantities (pressure difference, temperature difference, and relative difference of the mass flow) plotted against the cell count in Fig 6. As can be seen from the Fig. 7, the mesh with approximately $2 \times 10^{6}$ cells is a good mesh because by doubling the number of the cells for the next mesh we see only a $4 \%$ difference in the results, also for this mesh the mass flow error is around $1 \%$
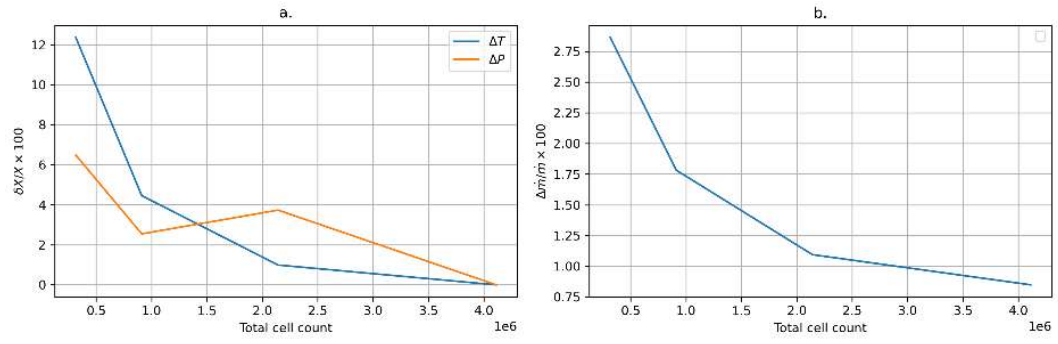

Fig. 7. Mesh independence

To compare the simulation performances, we must transform the data obtained from simulation into dimensionless quantities. As we considered the wall temperature to be constant, we can use logarithmic temperature difference to calculate the Nusselt using the equations below:

$$
\Delta T_{m l n}=\frac{T_{\text {out }}-T_{\text {in }}}{\ln \left(\frac{T_{w}-T_{\text {in }}}{T_{w}-T_{\text {out }}}\right)} \#(1)
$$

where $T_{\text {in }}$ and $T_{\text {out }}$ are the inlet and outlet temperatures, $T_{w}$ is the wall temperature.

The heat rejection can be calculated as:

$$
\dot{Q}=\dot{m} c_{p} \Delta T=k A \cdot \Delta T_{m l n} \Rightarrow k A=\frac{\dot{Q}}{\Delta T_{m l n}} \#(2)
$$

From equation (2) we can find the overall heat transfer coefficient $\mathrm{kA}$ which can be written in the form of a thermal resistance as follows: 


$$
\begin{aligned}
& \frac{1}{k A}=R_{\text {conv }}+R_{\text {cond }} \\
& R_{\text {conv }}=\frac{1}{\alpha \cdot \eta \cdot A} \#(3) \\
& R_{\text {cond }}=\frac{\delta}{\lambda_{A l} \cdot A_{w}}
\end{aligned}
$$

Because we have imposed a constant temperature $\mathrm{T}_{\mathrm{w}}=88.4{ }^{\circ} \mathrm{C}$ we can consider that $\delta=0$ which in equation (3) results that $R_{\text {cond }} \rightarrow 0$ and we arrive at the final form in the equation (4) below:

$$
\frac{1}{k A}=R_{\text {conv }}=\frac{1}{\alpha \cdot \eta \cdot A} \#(4)
$$

Considering the fin efficiency $(\eta)$ as 1 we can calculate Nusselt number with the equation (5) as follows:

$$
N u=\frac{\alpha \cdot D_{h}}{\lambda_{\text {air }}}=\frac{\dot{Q}}{A \cdot \Delta T_{\text {mln }}} \cdot \frac{D_{h}}{\lambda_{\text {air }}} \#(5)
$$

Calculation of the friction coefficient is straight forward and can be calculated form the equation (6) [1] directly:

$$
f=\frac{A_{c}}{A} \cdot \frac{2 \Delta p}{\rho \cdot v^{2}} \#(6)
$$

With these quantities defined we can make a comparison of the simulation with the experimental results. As we can see form the Fig. 8 the difference in thermal performance (Nusselt) is around $\pm 11 \%$ which it is considered an acceptable deviation. For the friction coefficient the deviation is greater reaching $-20 \%$, but this can be accounted if we consider that the simulations were done without considering the roughness of the material, and also because in reality the fins are not perfect which may induce higher pressure drop.
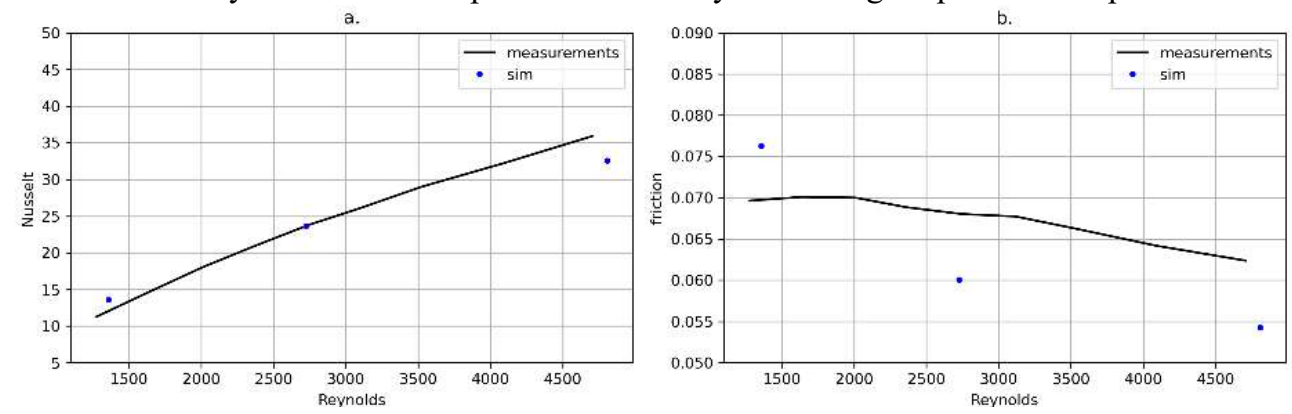

Fig. 8. Comparison of the simulation results with experimental results. a. Nusselt comparison, b. friction comparison

\section{Results and discussions}

For the current analysis 3 amplitude values (A) were chosen with the results presented in the form of Colburn number (j) and friction coefficient (f) in Fig. 9. 

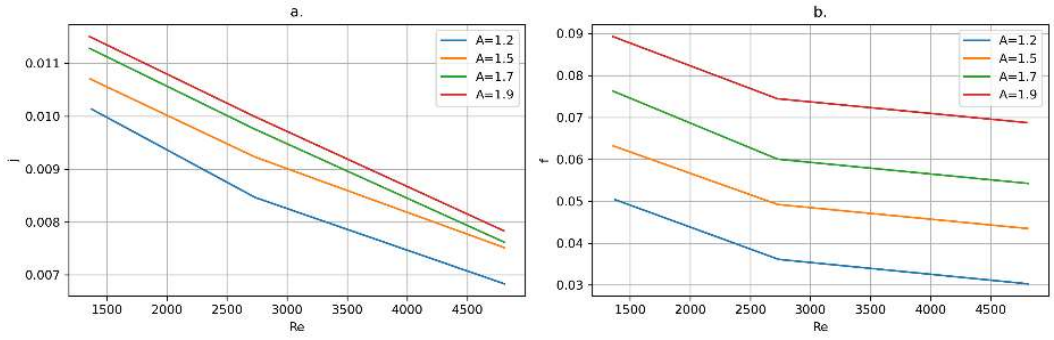

Fig. 9 Colburn and friction coefficient

The Colburn number rises with the amplitude, but we can see that for values of $A=1.5$, and $\mathrm{A}=1.9$ the difference is small. As a first conclusion that can be drawn is that increasing the amplitude gives us diminishing returns. If we analyze the Fig. 9b, we can see that the friction coefficient has a similar dependency of the amplitude, it rises with the amplitude. To assess the overall performance of the wavy fin we must use another factor which is a combination of the two factors from the Fig. 9. In [20] it is defined a factor called JF which takes into consideration the ratio of the Colburn number and friction coefficient based on a reference performance value, as in equation (7)

$$
J F=\frac{j / f^{1 / 3}}{j_{r} / f_{r}^{1 / 3}} \#(7)
$$

In Fig. 10 we can see that as the amplitude of the wavy fin increases the JF factor drops. Since we had experimental values for the $A=1.7$ wavy fin we had choose this wavy fin as a reference.

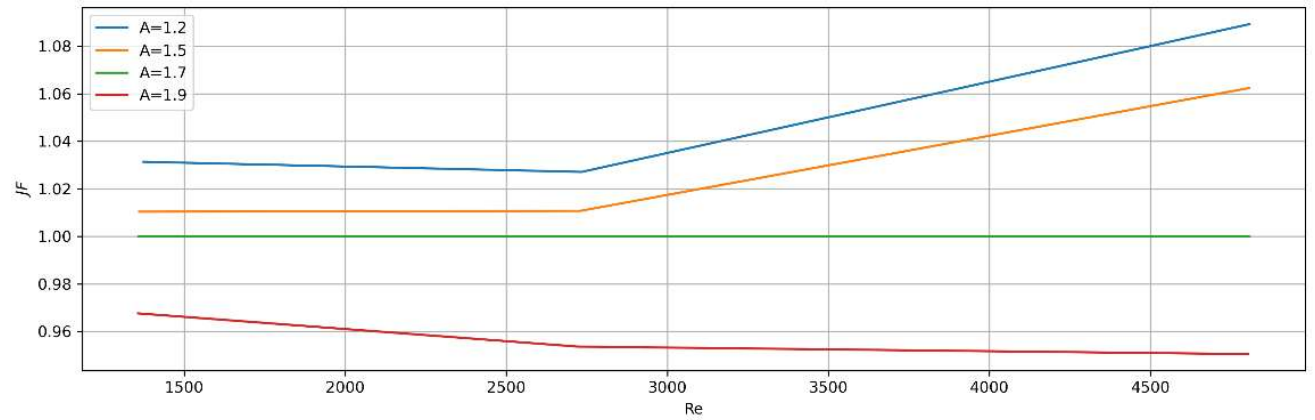

Fig. 10. JF factor comparison

The JF factor is a factor of type the "higher the better" that means that a higher value results in better performances. So, comparing the performances at different amplitudes A and at the same Reynolds number or speed - since the flow section doesn't change - it results that for the tested amplitudes the lower the amplitude the greater overall performances for the fin.

Considering that a heat exchanger in the real applications uses a fan to drive the cooling air through it, a higher value of JF at the same Reynolds number means that there is a reserve in pressure drop and in reality the heat exchanger will work with more air and also the heat rejection will be higher.

Having lower amplitude is good also from the clogging point of view because the passage is easier to traverse by the solid particles in the air. This translates in a longer service of the heat exchanger before cleaning maintenance is needed. 
As a future work there arises the need to investigate other amplitudes to see at which amplitude we find an optimum.

\section{References}

1. W. Kays and A. London, Compact heat exchangers, Third ed. New York: McGrawHill, (1984)

2. R. J. G. BEng and T. T. Al-Shemmeri, Proc. Inst. Mech. Eng. Part A J. Power Energy, 208, 225-229, (1994)

3. J. Zhang, J. Kundu, and R. M. Manglik, Int. J. Heat Mass Transf., 47, 1719-1730, (2004)

4. H. M. Metwally and R. M. Manglik, Int. J. Heat Mass Transf., 47, 2283-2292, (2004)

5. [5] C. C. Wang and C. K. Chen, Numer. Heat Transf. Part A Appl., 48, 879-900, (2005)

6. M. Gradeck, B. Hoareau, and M. Lebouché, Int. J. Heat Mass Transf., 48, 1909-1915, (2005)

7. L. S. Ismail and R. Velraj, Numer. Heat Transf. Part A Appl., 56, pp. 987-1005, (2009)

8. J. Dong, J. Chen, W. Zhang, and J. Hu, Appl. Therm. Eng., 30, 1377-1386, (2010)

9. J. Dong, C. Jiangping, C. Zhijiu, Z. Yimin, and Z. Wenfeng, Appl. Therm. Eng., 27, 2066-2073, (2007)

10. J. Dong, L. Su, Q. Chen, and W. Xu, Appl. Therm. Eng., 51, 32-39, (2013)

11. M. K. Aliabadi, F. Hormozi, and E. H. Rad, Int. J. Numer. Methods Heat Fluid Flow, 24, 1086-1108, (2014)

12. G. W. Kim, H. M. Lim, and G. H. Rhee, Int. J. Heat Mass Transf., 96, 110-117, (2016)

13. L. Xiao, T. Wu, S. Feng, X. Du, and L. Yang, Int. J. Heat Mass Transf., 110, 383-392, (2017)

14. N. A. A. Qasem and S. M. Zubair, Int. J. Refrig., 97, 21-30, (2019)

15. V. Marţian, M. Nagi, S. Albețel, and M. Sucilă, 13th Uk Heat transfer Conference, UKHTC2013/26, (2013)

16. S. Albețel, M. Vlad, and M. Nagi, Appl. Mech. Mater., 659, 283-288, (2014)

17. A. Association Française de Normalisation, "NF EN ISO 5167-2.” p. 56, (2003)

18. F. P. Incropera, D. P. DeWitt, T. L. Bergman, and A. S. Lavine, Fundamentals of Heat and Mass Transfer, 6th ed. Wiley \& sons, (2006).

19. SolidWorks Corp., Technical reference SOLIDWORKS FLOW SIMULATION 2018, (2018)

20. J. Yun and K. Lee, Int. J. Heat Mass Transf., 43, 2529-2539, (2000) 